\title{
INTERSECTION PROPERTIES FOR CONES OF MONOTONE AND CONVEX FUNCTIONS IN SCALE OF LIPSCHITZ SPACES
}

\author{
INNA KOZLOV
}

Abstract. The basic results of the real interpolation method is known to be valid for couples $\left(X_{0} \cap Q, X_{1} \cap Q\right)$ under the condition that the cone $Q$ has the so-called intersection property with respect to the couple $\left(X_{0}, X_{1}\right)$. In this paper we study this property for the cones of monotone and convex functions with respect to the couple of Lipschitz (Nikol'skii-Besov) spaces.

\section{Mathematics subject classification (2000): 46B70.}

Key words and phrases: Intersection property, real interpolation method, Lipschitz (Nikol'skii-Besov) spaces, cones of monotone and convex functions.

\section{REFERENCES}

[1] I. AseKritova, On the $K$ - functional of the couple $\left(K_{\Phi_{0}}(\bar{X}), K_{\Phi_{1}}(\bar{X})\right)$, Studies in the Theory of Functions of Several Real Variables, Yaroslavl, 1980, 3-31 (in Russian).

[2] J. BERGH AND J. LÖFSTRÖM, Interpolation spaces, Springer, Berlin (1976).

[3] YU. BRUdNYI, On a theorem of local best approximation, Kazan Gos. Univ. Uchen. Zap. 124 (1964), 43-49, MR32 2808.

[4] Yu. BRUdNYI, N. KRUGLJAK, Interpolation Functors and Interpolation Spaces, Volume 1, 1991, North Holland.

[5] J. CERDÀ AND J. MARTín, Interpolation of operators on decreasing functions, Math. Scand., 78 (1996), $233-245$.

[6] J. CERDÀ AND J. MARTÍN, Interpolation of some cones of function spaces, Preprint.

[7] C. S. HERZ, Lipschitz spaces and Bernstein's theorem on absolutely convergent Fourier transforms, in: Journal of Mathematics and Mechanics, Vol. 18, No. 4 (1968).

[8] T. HolmstedT, Interpolation of quasi-normed spaces, Math. Scand. 26 (1970), 177-199.

[9] I. KozLov, Interpolation and Approximation in Banach Spaces with a Cone, Ph.D. Thesis, 1997.

[10] S. NIKOL'SKII, Approximation of functions of several variables and imbedding theorems, Springer-Verlag (1975).

[11] J. PeETRE, Espaces d'interpolation et théoreme de Sobolev, Ann. Inst. Fourier, 1966, 16, N1, 279-317.

[12] Y. SAGHER, Some remarks in interpolation of operators and Fourier coefficients, Studia Math.44, 239-252 (1972).

[13] Y. SAGHER, An application of interpolation theory to Fourier series, Studia Math. 41, 169-181 (1972).

[14] A. F. Timan, Approximation Theory of Real Variable Functions. Gos. Izd. Fiz.-Mat. Lit., Moscow, 1960. 